\title{
Value Chain and Customer Relationship Cycle:Two Concepts of Relationship Marketing
}

\author{
DUMITRESCU Luigi, ICHINDELEAN Mihai
}

\begin{abstract}
The globalization and digitalization of the world's economies have created the premises for the assertion of relationship marketing as theory and practice of modern marketing. A main strategic dimension of the relationship marketing concept is represented by the strategy of gaining customer fidelity, which has as a primary purpose the extension of the client retention towards the company. Setting as a leading goal the client's rational/emotional fidelity, the strategy of gaining customer fidelity implies two positive effects for the company: individualizing the relationship with the client and improving the company's performance. The development of the strategy implying gaining customer fidelity is conditioned by the manner in which a company can operate with three variables: customer satisfaction, customer fidelity and customer loyalty. Modeling in a correct manner these three variables enables the company to segment the relevant market in profitable ways. The paper is based on the theoretical background of value chain - an important concept in the relationship marketing theory. Thus, motivation was only defined as a company external factor which influences the psychological effects within the customers' minds. Perceived satisfaction was used as a psychological variable and loyalty as a behavioral variable. The correlation between these two variables reveals some insights about the mental processes that determine the consumer behavior.
\end{abstract}

Index Terms - relationship marketing, customer satisfaction, customer fidelity, customer loyalty, customer motivation, customer relationship cycle, value chain.

\section{INTRODUCTION}

By aiming the development of a durable relationship between the company and its end customers, relationship marketing targets the fulfillment of the following three main objectives: 1) attracting customers; 2) gaining the fidelity of existing customers; 3) renewing the company's image [L. Dumitrescu, C. Apostu, 2009].

Gaining the fidelity of the existing customers is a process which assumes a differentiation and a separate analysis of the customer relationship phases. To formulate or develop strategic and operative recommendations for each of these phases, it was necessary to include the concept of life cycle in the area of the customer relationships. Thus, three customer life cycles where identified: 1) The customer life length cycle;

DUMITRESCU Luigi, Professor, PhD, Faculty of Economic Sciences "Lucian Blaga" University Sibiu, Romania (E-mail: luigi.dumitrescu@yahoo.com)

ICHINDELEAN Mihai, PhD Candidate, Faculty of Economic Sciences "Lucian Blaga" University Sibiu, Romania ( E-mail: mihaitichi@yahoo.com)
2) The customer episode cycle and 3) The customer relationship cycle [B. Stauss, 2000].

In this view, knowing the determinant factors upon which a strategy of gaining the customer fidelity is developed, starts with solving the following three main problems which constitute the content of this paper: 1) identifying the phases of the three earlier mentioned life cycles; 2) operating the concepts of satisfaction, fidelity and loyalty and 3) segmenting the market based on the correlation between satisfaction and loyalty.

\section{The CUStomer Relationship CyCle And VAlue CHAIN}

By analyzing the phases of the customer relationship cycle, a company can identify the intensity of its relationship with a certain client. In this view, three categories of indicators are relevant to characterize the intensity of the relationship: 1) psychological indicators (price/utility rate, relationship quality from the client's perspective, client satisfaction etc.); 2) behavioral indicators (client retention, information behavior, integration behavior, communication behavior); 3) economic indicators (turnover, market share, client value etc.).

The phases of a client's relationship cycle can reveal some useful insights for the company:

+ The attraction phase of a client describes the beginning of a company's relationship with a certain client and contains an initiation phase (the client accumulates information and the company undertakes actions in order to attract the client) and a socializing phase (the client accumulates his first experiences with the company's performance and evaluates the performance's quality).

+ The client retention phase represents an extension of the relationship which occurs between the company and the client and is subdivided into two phases: a growing phase and a maturity phase.

+ The client regaining phase ends the relationship cycle of a client and it contains a danger phase (the client thinks that he does not wish to benefit from the company's performance anymore) and a dissolution phase (the client does not use the company's offer anymore).

The customer relationship cycle represents a dynamic form of contacts between the customer (seen as an individual or as a segment) and the company. These contacts are measured through several variables or indicators: psychological, behavioral and economic indicators [Bruhn, 2009] which emphasize the relationship intensity. By studying the customer relationship cycle, the company observes the present results or effects (i.e. relationship quality from the 
client's perspective, client satisfaction and client share) from the client's (demand) perspective.

Customer relationships can be measured through the value chain. Value chain is another important concept in the relationship marketing literature which structures a customer relationship by taking into consideration both the supply (company) and demand (perspective). The underlying idea of this concept is that company and customer specific variables are interacting in different directions and with different intensities generating a result. The value chain perspective of a customer relationship should be studied as a logical succession of four "cells", in which each cell is the cause for the next cell:

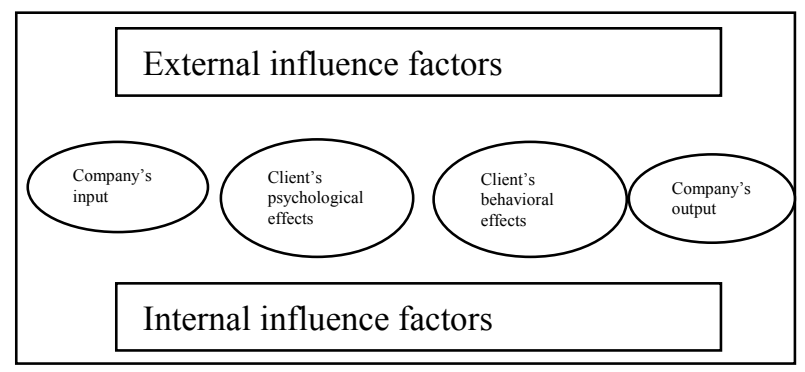

Figure 1 - The value chain concept [Bruhn, 2009]

The company's input includes all the actions or instruments specific to the relationship marketing through which one company consciously interacts with its customers. These actions represent a form of impulse or stimuli which generate psychological effects in the customers' minds (i.e. the customer perceives a higher service quality as an effect of employee training, the customer feels a higher satisfaction level regarding the company's product as an effect of cross-buying). The obtained psychological effects are considered to be causes for the consumer behavior (behavioral effects) which can be observed and measured with the use of variables like: rebuying, Cross-buying, recommendation etc. The value chain ends with the company's output, namely the company's monetary benefits (variables like Customer Lifetime Value, revenues, profit margin, Share of Wallet etc.) as results from the succession of the first three "cells". If a customer relationship is understood through the value chain concept, the company should carefully take into consideration other factors (not included in the four "cells") which can influence every "cell" of the value chain: influence factors which are external to the company (market dynamics, changes in lifestyle, heterogeneity of clients' expectations etc.) and influence factors which are internal regarding the company (shift in company's culture, price setting restrictions, personnel migration etc.).

Although the value chain concept is a logical construct based on a logical succession of "cells" which offers relevant relational insights to the company (i.e. regarding the present value of the customer relationship, the cause-effect links between several variables as factors for the value of the customer relationship) there is only one way on the direction: company's input $\rightarrow$ psychological effects $\rightarrow$ behavioral effects $\rightarrow$ company's outcome (together with the external and internal influence factors). In practice, a customer relationship is a living construct in which the elements of the value chain are connected not only through a double sense direction (i.e. the reported profits of the company known by the customers may influence their buying behavior), but also characterized by the interchangeability of the "cells" (i.e. mental structures which amplify when related - perceived satisfaction and remembered dissatisfaction - without generating a short-term buying behavior). A customer relationship is to be analyzed as a complex system, namely a system of heterogenic components which through their non-linear interaction generate emerging behavior specific for the whole system and not just for parts of it.

The simultaneous use of the two relationship marketing concepts (Customer relationship cycle and value chain) enables permanent access to information regarding the linkage for a certain phase of the customer relationship cycle - company's input - psychological effects - behavioral effects - company's outcome.

\section{The Concepts of Motivation, Customer SATISFACTION, Fidelity AND LOYALTY}

Motivation is a mental construct defined by psychologists as the dynamic aspect of a subject's entrance in a relationship with the environment, its active guidance of its behavior towards a category of preferred objects or situations [Zlate, 2006]. Thus, motivation is seen as an energy release, a learned reaction associated with stimuli, a factor which influences the behavior and as a cause which explains the change of a repose state into an action state.

In the classic theory of Consumer behavior, motivation is considered to have its origins in needs and goals, acting as a spur to learning [Schiffmann, Kanuk, 2009]. Other authors include motivation (along with perception, personality, learning and attitude) within the category of endogenous factors which have an influence on the consumer behavior that can only by deduced [Catoiu, 2004].

Due to the fact that motivation is, along other mental constructs, a condition or a trigger for action or inaction, it can be stated that its influence on the consumer behavior is positive or negative. In this line of ideas, some authors [Percy 1997] consider motivation as a negative (based on fear or hate) or positive reinforcement (based on needs or desire) of the consumer behavior. Other authors [Vollerrand 1997] perceive motivation in relation with the object whose needs are trying to be satisfied. Thus, a difference can be made between intrinsic motivation (the object whose needs are trying to be satisfied is the subject itself; functional motivation, hedonistic motivation and cognitive motivation) and extrinsic motivation (the object whose needs are trying to be satisfied is the society; social motivation).

In our opinion, motivation is a mental process which begins with an inherent state of tension caused by one or more unsatisfied needs and ends with building up coherent motives that trigger some known behavior (i.e. buying behavior). According to their origins (or needs upon they are build on), motives can be primal or biological motives and secondary or psychogenic motives. Another classification divides motives in two categories (reason is used as classification criterion): rational motives (i.e. functionality, 
durability, utility etc.) and emotional motives (i.e. pride, social status, ambition, etc.) [Catoiu, 2004].

When considering relationship marketing from the value chain perspective, motivation is one of the external factors which, along others (perception, attitude and learning) have a significant influence on the psychological effects of the consumer, thus generating particular behavioral effects. By studying the various buying motives, the company can identify clusters of behavioral effects based on motive similarities. Such relevant information can be used by the company as an input in the value chain process.

Future efforts of the authors will be oriented towards a motivational segmentation of the fuel market (retail clients) of Sibiu, Romania and an estimation of the Customer Lifetime Value of each identified segment.

The evaluation phase of the customer orientation process [M. Bruhn, 2001] starts with the analysis of client satisfaction. Satisfaction is defined as the result of a complex information analysis process performed by the client. [Oliver R.L., Swan, J.E, 1989]. Bloemer [1998] defines the client satisfaction towards a certain brand/product as the felt experience after the consumption, a subjective evaluation of the measure in which the client's initial expectations are met by the company's performance. Ph. Kotler [2008] argues that satisfaction appears as a feeling of pleasure or disappointment experienced by a client when he compares his perception of the company's performance with his initial expectations regarding that particular performance. The several satisfaction levels should be carefully studied by the company due to the fact that the customer satisfaction represents the main impact factor of the customer's fidelity or loyalty towards the company. According to the value chain concept, satisfaction is considered, along other mental structures (perceived quality, perceived value, customer expectations) to be a psychological effects influenced by the company's input and other consumer internal and external factors.

The customer's fidelity is the result of the felt satisfaction after the consumption of a product/service. Some authors consider that customer fidelity is obtained when his initial expectations regarding the company's performance are equal to his "after consumption" perception. Fidelity is state-of-mind of the customer, which resulted after an evaluation process. This process can be partially influenced by the company through the use of specific actions for earning client fidelity, actions which gravitate around the four variables of the marketing-mix. Bruhn defines the client fidelity as an assembly of a company's measures which target the positive orientation of the behavioral intentions of the actual and future clients towards a company's offer, with the purpose of obtaining a client relationship stabilization and development, respectively. The two concepts (fidelity and gaining customer fidelity) are significantly different: customer fidelity is specific for the demand holder (the client attaches himself to the company), while gaining customer fidelity is specific for the supplier (i.e. the company).

The customer loyalty is considered to be a superior state of customer fidelity. A precise difference must be made between a fragile loyalty and a complete loyalty. The development of fragile loyalty can be considered the basis for reaching a complete client loyalty. For the establishment of a client's loyalty, a company should measure the following five relative dimensions of the consumer behavior within a certain period of time: the percentage of clients who buy a certain product; their buying frequency, the percentage of clients who buy a certain brand, the percentage of clients who are completely loyal and the percentage of clients who buy other brands [Ehrenberg, 1988]. From a psychological point of view, there are three aspects of the human psyche (affect, cognition and conation) which have a direct influence on the level of customer loyalty, but with distinct intensities.

Finally, it should be assessed the fact that customer loyalty depends also on a second dimension (along with the behavioral dimension) - the customer's attitude. Loyalty based on attitude represents a customer long term engagement and cannot be determined by the simple observation of the buying behavior.

Within the value chain theory, client loyalty is considered to be a behavioral effect. Knowing the linkage or the correlation between client satisfaction and client loyalty represents a relevant insight of the mental processes (in our case - satisfaction) that govern the consumer behavior (in our case - client loyalty).

If a company's main purpose is to obtain a complete customer loyalty, it should target its marketing efforts in attaining a behavioral and an attitudinal loyalty of its clients. The two loyalty dimensions should be measured and saved within a database. By analyzing the saved data, a company gets insights regarding three useful marketing actions: building a behavioral loyalty, cultivating attitudinal loyalty and correlating loyalty with client profitability.

\section{RESEARCH Methodology}

The presented theoretical background within the first three sections of this paper can be used by a company to segment its relevant market based on the correlation between customer satisfaction and the equivalent loyalty. In this view, the authors will present the process of the retail market segmentation of Mol România Petroleum Products SRL, based on the correlation between the customer satisfaction and the corresponded loyalty. The undertaken marketing research respects the three phases of the marketing research process.

Within the preliminary phase, the authors identified the following possible problem definition of the examined company, Mol România Petroleum Products SRL (further named the company): determining the maintenance rate of actual retail customer share. Based on this mentioned decision problem, the purpose of this research is to segment the relevant retail market of the company within the area of the Sibiu town based on the possible correlation between customer satisfaction and the corresponded loyalty. To attain this purpose, seven objectives with their associated hypothesis were established.

The design phase contains research activities which have as goals identifying of the needed sources of information, choosing the data gathering method, systemizing the information and planning the research over a period of time. The sources of information used in this research are an 
external source (a source from the company's marketing environment) and a primary source (primary data used to achieve this research's main purpose). The first six used variables are measured with an interval scale in general, a differential semantic scale, in particular, with nine intervals and 10 points. The points represent a synthesis of the mental process performed by the clients when answering each question. The last three variables are measured through three nominal scales. The three variables (age, education level and income) are categorical variables with a limited number of states or options (4, 7 and 5, respectively).

The present research uses as a method the survey. A survey is defined as a gathering method of primary data, based on a questionnaire which is administrated to a representative sample of respondents [Catoiu, 2009]. The used questionnaire was administrated during a time period of ten days, between 5 March and 15 March 2010, within the online and "offline" environment. The gathered data has constituted the necessary informational input for creating a database within the statistic analyzing software PASW 18.0. The created database contains 9 columns ( 9 used variables) and 139 rows (number of observations).

According to the settled objectives and the scale types, specific statistical methods were used.

In this research, the following elements were established, for the measurement of customer satisfaction (within the four variable: S1, S2, S3 and S4 ): descriptive statistics elements (mean and standard deviation), values of the simple or linear correlation coefficient (an indicator which measures the intensity level of the association between the factorial variable and the result variable) and the p-value (the probability of obtaining a value of the simple correlation coefficient due to chance).

The sign $(+)$ of the values of the correlation coefficient indicates the existence of a positive correlation (correlation direction) and the values of this coefficient measure the intensity of the correlations between the four analyzed variables. The correlation with the highest intensity is found between variable S1 and variable S3 - a high level of satisfaction regarding the company's brands implies a high level of satisfaction regarding the company's brands in comparison with other competitors' brands (the value of 0.711 can be interpreted as follows: $71.1 \%$ of the $\mathrm{S} 1$ variable's variance is due to the variance of S3). The correlation with the lowest intensity is found between variables S3 and S2. This low intensity can be explained through the fact that the customer's initial expectations are fulfilled in a better manner by the competitors' performance, rather than by the company's one.

The $\mathrm{p}$-value is 0.00 for all the settled correlations, leads to the rejection of the null hypothesis $\left(\mathrm{H}_{0}\right)$, which presumes that there is no correlation between the variables.

The mean values of the four analyzed variables $(7,64$ for S1 - general satisfaction, 7,44 - satisfaction based on the initial expectations, 7,28 - satisfaction in comparison with the competitors and 7,15 - customer's image of the company) are higher than the mean value of the scale $(4,5)$; and these results confirm the first four hypothesis associated to the first four objectives of the research.

The same statistical methods were used to determine the descriptive statistics elements and the values of the linear correlation coefficient for the next considered variables (L1 Customer loyalty based on their buying intention and L2 Customer loyalty based on a price growth scenario), which measure customer loyalty. A strong positive correlation $(+0.718)$ exists between the two considered variables; the variance of the $\mathrm{L} 1$ variable is explained in a ratio of $71,8 \%$ by the variance of the L2 variable. Thus, a high score obtained by the first variable (L1 - Customer loyalty based on their buying intention) implies a high score for the second variable (L2 - Customer loyalty based on a price growth scenario); the customer who manifests his/hers buying intention would buy the company's brands in a $10 \%$ price growth scenario (the opposite situation is also valid). The high value of 2,497 of the standard deviation (for L1) shows that the scores for this variable are not grouped around the mean, thus there is heterogeneity CFD of this variable.

The mean value of the first variable (L1) is 7.05 higher than the mean value of the scale, which confirms the fifth hypothesis associated to the fifth objective.

The mean value of the second variable (L2) is 5.32 lower than the mean value of the scale, and this result rejects the sixth hypothesis associated to the sixth objective. In this regard, the authors affirm that the respondents are highly price sensitive, resulting in a low attitudinal loyalty.

The $p$-value is 0.00 for the settled correlation, rejecting the null hypothesis of the chi test.

To achieve a segmentation of the company's retail market, based on the correlation between the customer satisfaction and their loyalty, the authors created two more variables (Total satisfaction and Total loyalty) based on the four initial variables (S1, S2, S3 and S4), which measure different aspects of customer satisfaction and on the two initial variables (L1 and L2), which measure different aspects of customer loyalty. The new created variables are characterized by variation, which is influenced by the variation of the initial variables. In this view, the authors used the procedure of Data Reduction - Factor, with the extraction method Alpha Factoring.

The Alpha Factoring method presumes the creation of a number of factors (new variables) equal to the number of the initial variables (for Total Satisfaction there are four initial factors). These factors are created through linear algebraic combinations of the first four initial variables that are weighted with the variance of one variable common to the variance of the other three variables. An Initial Eigenvalue of 1 means that the created factor absorbs $100 \%$ of the variation of one variable. The result of applying this method was the creation of one factor, whose Initial Eigenvalue is 2.905, absorbing $290.5 \%$ of the total variance $(400 \%)$ of the initial four variables. Thus, this factor is considered to be the new created variable of Total satisfaction.

The same procedure was used to create a second new variable (Total Loyalty), whose variation is influenced by the variation of the initial two variables (L1 - Customer loyalty based on their buying intention and L2 - Customer loyalty based on a price growth scenario). The variation of the new created variable (Total Loyalty) is influenced in the same ratio $(85.7 \%)$ by the variation of the two initial variables and absorbs $143.4 \%$ of the total variance $(200 \%)$ of the initial two 
variables.

The two created variables (Total satisfaction and Total loyalty) were used as segmentation variables within the PASW 18 procedure: Classify -TwoStep Cluster. In this regard, a finite number (4) of market segments was created, which significantly differ according to the correlation levels between the newly created variables (Total satisfaction and Total Loyalty). The identified segments were characterized through the three nominal variables (age, education level and income) with the purpose of achieving clients' profiles.

Segment no. 1 is characterized by a strong positive correlation between the total satisfaction and total loyalty. Thus, a high level of satisfaction implies a high level of loyalty.

Segment no.3 contains a weak positive correlation between the total satisfaction and total loyalty. Clientswithin this segment manifest a weak satisfaction and a weak loyalty regarding the company's brands.

Segment no. 4 is characterized by a strong negative or inverse correlation between the total satisfaction and total loyalty. Although the members of this segment are not satisfied with the company's performance they are loyal to the brand.

Segment no.2 contains a strong negative correlation between total satisfaction and total loyalty. Clients within this segment manifest high levels of satisfaction, but low levels of loyalty.

These results can be structured in a bidimensional diagram which has as abscise the levels of loyalty and as ordinate the levels of satisfaction. (Figure 1), as follows:

\begin{tabular}{r|l|l|}
\multicolumn{1}{r}{$\begin{array}{r}\text { High } \\
\text { satisfaction }\end{array}$} & $\begin{array}{l}\text { Segment } \\
\text { no.2 }\end{array}$ & Segment no.1 \\
\cline { 2 - 3 } $\begin{array}{r}\text { Low } \\
\text { satisfaction }\end{array}$ & $\begin{array}{l}\text { Segment } \\
\text { no.3 }\end{array}$ & Segment no.4 \\
\cline { 2 - 3 } & &
\end{tabular}

Low loyalty

High loyalty

Figure 2 - Identified market segments based on the correlation between the customer total satisfaction and total loyalty

The persons of the first segment (high level of satisfaction which implies a high level of loyalty) are characterized by an age range between 31-40 years, highly educated (Bachelor Degree, Master Degree or PhD) and earn a high income (over $52 \%$ of the members have had the last income over 3001 Lei (700 Euro) /month.

The members of the second segment (high satisfaction/low loyalty) are young people (between 18 and 30 years old), with Bachelor Degrees (82\% of the members) and have medium incomes (between 1001 and 1500 Lei - between 230 and 350 Euro/month) or high incomes (over 3001 Lei - 700 Euro/month). The main characteristic of these persons is their price sensibility. Although they are satisfied by the company's performance, they will migrate to the competition in the case of a price growth of the company's brands.
The persons which form the third segment (low level of satisfaction that implies a low level of loyalty) are young people, with Bachelor Degrees and low or medium incomes (34\% have a gross income under 1000 Lei - 230 Euro/month, $39 \%$ earn a gross income between 1501 and 2000 Lei -350 Euro and 450 Euro/month and $27 \%$ a gross income between 2001 and 3000 Lei - 450 Euro and 700 Euro/month). Based on these demographic characteristics, they are not satisfied with the company's performance which implies a low loyalty (idea of multi-brand loyalty).

The members of the last segment (4) are young people ( $97 \%$ with an age range between 18 and 30 years), are highly educated (91\% have a Masters Degree) with a relative uniform distribution of income among them. Being young and educated people, the members of this segment are aware of the dimensions of the performance's quality, thus they have high initial expectations. The initial expectation level exceeds the company's performance, creating a feeling of low satisfaction or even dissatisfaction. Being aware of this feeling, they ignore it and continue to repurchase (behavioral loyalty) the company's brands, demonstrating their attitudinal loyalty to the company.

\section{CONCLUSIONS AND FUtURE RECOMMENDATION}

The main purpose of this paper is to review and extend the literature regarding the link between the satisfaction felt by the customers after products/services consumption and their loyalty towards them. In this view, the paper has been structured in three parts; the first two parts describe the theoretical background of the concepts used in the research client's relationship cycle, value chain, motivation, customer's satisfaction, fidelity and loyalty. The third part contains a marketing research which had as main goal the segmentation of the retail market of Mol Romania Petroleum Products (in the town of Sibiu) based on the existing correlation between the satisfaction felt by the clients and their loyalty. The data were analyzed by using the procedures of the statistical software PASW18. Four retail market segments have been found, which differ significantly one from the other, based on the different degrees of correlation between customers satisfaction and their loyalty. The segments found were characterized through three categorical variables (age, education level and income level). The most important aspect of the obtained results relies in the empirical confirmation of the theoretical differentiation between behavioral loyalty and attitudinal loyalty of the customers (segment 4).

The research is based on the theoretical background of value chain - an important concept in the relationship marketing theory. Thus, motivation was only defined as a company external factor which influences the psychological effects within the customers' minds. Perceived satisfaction was used as a psychological variable and loyalty as a behavioral variable. The correlation between these two variables reveals some insights about the mental processes that determine the consumer behavior.

Future research should be oriented towards a market segmentation based on the customer's buying motives and 
their description based on the satisfaction-loyalty correlation. Also, the authors will try to evaluate the monetary value of these segments, with the purpose of developing instruments for customer retention.

\section{REFERENCES}

[1] J. Bloemer, K. de Ruyter, "On the relationship between store image, store satisfaction and store loyalty", European Journal of Marketing, 1998.

[2] M. Bruhn, and S. Michalski, "Ruckgewinnungsmanagement. Eine explorative Studie zum Stand des Ruckgewinnungsmanagementes bei Banken un Versicherungen", Die Unternehemung, 2001.

[3] M.Bruhn, "Relationship Marketing. Das Management von Kundenbeziehungen”, 2te Auflage, Vahlen Verlag, Munchen, 2009.

[4] I.Cătoiu (Coordinator), "Marketing Research", 2nd Edition, Ed.Uranus, Bucuresti, 2009.

[5] I.Cătoiu, and N. Teodorescu, "Consumer Behavior", 2nd Edition, Ed.Uranus, Bucuresti, 2004.

[6] L. Dumitrescu, and C. Apostu, "Marketing and service quality," Ed. Expert, 2009.
[7] A. Ehrenberg, "Repeat buying: Theory and applications (2nd edition)", London, Charles Griffin \& Co, 1988.

[8] Ph.Kotler, J.Keller, "Marketing Management", 5th Edition, Ed.Teora, Bucuresti, 2008.

[9] R.L. Oliver, J.E. Swan, "Customer perceptions of interpersonal equity and satisfaction in transactions", Journal of Marketing, 1989.

[10] M. P. Pritchard, D. A. Howard, and M. E. Havitz, "Loyalty measurement: A critical examination and theoretical extension", Management Science, 38, 1992 155-164.

[11] J. R. Rossiter, and L. Percy, "Advertising communication and promotion management", London, McGrawHill, 1997

[12] J.W. Reinartz, and V. Kumar : "The mismanagement of customer loyalty”, Harvard Business Review, 80(7), 2002.

[13] L.G. Schiffman, and L.L. Kanuk, "Consumer Behavior", 9th Edition, Pearson Education, New Jersey, 2009.

[14] B. Stauss, "Augenblicke der Wahrheit" in der Dienstleistungserstellung. Ihre Relevanz und ihre Messung mit Hilfe der Kontaktpunkt-Analyse, 3.Aufl., Wiesbaden.

[15] R.J. Vallerrand, "Toward a hierachical model of intrisec and extrinsec motivation", in Advances in experimental and social psychology, New York, Academic Press, 1997.

[16] M. Zlate, "Basics of psycholigy", Ed. Universitara, 2006, Bucuresti 